\title{
Exposure to Ambient Air Pollutions and Upper Respiratory Tract Infection in Zhengzhou City, China: A Approximate Five-Year Surveillance Study
}

\author{
Shan-shan Lin \\ Henan University of Traditional Chinese Medicine \\ Hui hui He \\ Henan University of Traditional Chinese Medicine \\ Rui Jia \\ Henan University of Traditional Chinese Medicine \\ Juan Du \\ Henan University of Traditional Chinese Medicine \\ Ning yi Ma \\ Henan University of Traditional Chinese Medicine \\ Meng dan Qian \\ Henan University of Traditional Chinese Medicine \\ Yan Wang \\ Henan University of Traditional Chinese Medicine \\ Hui min Huang \\ Henan University of Traditional Chinese Medicine \\ De qi Kong \\ Henan University of Traditional Chinese Medicine \\ Ya Li ( $\sim$ liya@hactcm.edu.cn ) \\ Henan University of Traditional Chinese Medicine
}

\section{Research}

Keywords: Air pollution, Upper respiratory tract infection, Time-series analysis, Distributed lag non-linear model

Posted Date: June 17th, 2021

DOI: https://doi.org/10.21203/rs.3.rs-584958/v1

License: (1) This work is licensed under a Creative Commons Attribution 4.0 International License. Read Full License 


\section{Abstract}

Background: Studies indicated that air pollutions were associated with respiratory disease have with a lag exposure-response relationship, but not linear. However, few evidences in Zhengzhou, one of the most polluted cities for China.

Method: Upper respiratory tract infection (URTI) outpatient visits in the hospital, meteorological parameters and air pollutions data were obtained from October 28, 2013 to May 1, 2018 and were used for evaluating the risk effects of the air pollutants with a distributed lag non-linear model (DLNM), including the stratified analysis of gender and age.

Result: 475013 cases were included, with obvious seasonal fluctuations,higher in cool/cold and lower in warm. Every increase of $10 \mu \mathrm{g} / \mathrm{m}^{3}$ of $\mathrm{PM}_{2.5}, \mathrm{PM}_{10}, \mathrm{SO}_{2}, \mathrm{NO}_{2}$ and $\mathrm{CO}$ showed similar impacts on URTI outpatient visits in different genders and age subgroups, within 0 to 15 days of lag. $\mathrm{PM}_{10}, \mathrm{SO}_{2}$ and $\mathrm{NO}_{2}$ had the strongest immediately risk at lag 0 [RR $\mathrm{RM}_{\mathrm{PM} 0}: 1.0011,95 \% \mathrm{Cl}(1.0002-$ 1.0020); $\mathrm{RR}_{\mathrm{SO} 2}: 1.0084,95 \% \mathrm{Cl}(1.0039-1.0130) ; \mathrm{RR}_{\mathrm{NO} 2}: 1.0149,95 \% \mathrm{Cl}:(1.0111-1.0188)$, respectively], while $\mathrm{PM}_{2.5}$ and CO got highest risk at lag 15 days [RR $\mathrm{RR}_{\mathrm{PM} .5}: 1.0014,95 \% \mathrm{Cl}(1.0003-1.0025) ; \mathrm{RR}_{\mathrm{CO}}: 1.0002,95 \% \mathrm{Cl}$ : (1.0001-1.0003), respectively]. In addition, calculating overall accumulated effects of each $10 \mu \mathrm{g} / \mathrm{m} 3$ increase in $\mathrm{PM}_{10}, \mathrm{SO}_{2}, \mathrm{NO}_{2}$, and $\mathrm{CO}$ was greater in females than in males, as well as greater in the adolescents (aged 0-18 years) and elderly (aged $\geq 60$ years) than in adults (aged 19-59 years), except CO was greater in the adolescents and adults than in the elderly. No significant cumulative effects were found in $\mathrm{PM}_{2.5} \cdot \mathrm{O}_{3}$ levelwasno significant correlation withURTI outpatient visits throughout the lag period.

Conclusions: Our results indicated that $\mathrm{PM}_{10}, \mathrm{SO}_{2}, \mathrm{NO}_{2}$ and $\mathrm{CO}$ had strong immediate and lag cumulative effects in the females, adolescents, and elderly. $\mathrm{PM}_{2.5}$ has lag effects but has no significant lag cumulative impact effects on gender and age.

\section{Introduction}

The World Health Organization considered health was threatened by air pollution, which was the largest environment risk, with $90 \%$ of people breathing in contaminated air every day and residents of developing countries experienced severer air pollutant problems ${ }^{1}$. The 2018 Environmental Performance Index report indicated China's air quality was poor, ranked 3rd from the bottom ${ }^{2}$. The air pollutants may mainly come from industrial pollution sources, fuel combustion and ground dust ${ }^{3}$, which are dynamic and complex mixtures of gaseous pollutants ( $\mathrm{NOX}, \mathrm{SO}_{2}, \mathrm{O}_{3}$ and $\mathrm{CO}$ ) and particulate matters $\left(\mathrm{PM}_{10} \text { and } \mathrm{PM}_{2.5}\right)^{4}$. Numerous researches showed that air pollutions could penetrate into the system of respiratory and circulatory, exacerbating pulmonary disease, damaging extrapulmonary organs ${ }^{5}$. And it also caused more harmful to vulnerable populations around the world, such as females, children, elderly, and people with low socioeconomic status ${ }^{6}$.

URTI is a common respiratory disease, and located in the upper respiratory tract ${ }^{7}$, which is the gateway to the lung and is more easily to be affected by air pollutants. A study in Hong Kong showed that URTI accounted for $26.4 \%$ of outpatients ${ }^{8}$. Another study from Turin, a city in northwestern Italy, showed that in the emergency hospital outpatient clinics, teenagers who came to the clinic due to respiratory infections account for $81 \%$ of adolescents with respiratory diseases ${ }^{9}$. Numerous reaches have revealed that long-term or short-term exposed to air pollutions $\left(\mathrm{PM}_{2.5}, \mathrm{PM}_{10}, \mathrm{SO}_{2}, \mathrm{NO}_{2}, \mathrm{CO}\right.$ and $\left.\mathrm{O}_{3}\right)$ related to respiratory diseases ${ }^{10,11}$. However, the researches on the association between air pollutions and clinic patients with URTI are relatively rare in China. For all we know, in China, only Beijing ${ }^{12}$, Shenyang ${ }^{13}$, Hefei ${ }^{14}$, Guangdong ${ }^{15}$, Hongkong ${ }^{16}$, Taiwan ${ }^{17}$, Wuhan ${ }^{18}$ have carried on study of the relationship between air pollutions and URTI, while in Henan Province has not been studied yet. Air pollutions and demographic characteristics are different in each region. It is necessary to research local particular conditions to provide ideas for local government to prevent and control pollutants, as well as clinical treatments.

\section{Materials And Methods}

\subsection{Research area}

Zhengzhou, the capital of Henan Province, is located in the southern part of the North China Plain $\left(112^{\circ} 42^{\prime}-114^{\circ} 13^{\prime} E, 34^{\circ} 16^{\prime}-34^{\circ} 58^{\prime} N\right)$. It belongs to the northern temperate continental monsoon climate, which is characterized by low rainfall, low temperatures, low humidity, and high frequencies of calm wind in autumn and winter, most of the time it belongs to static and stable weather. Zhengzhou has a special geographical location, bordering the Yellow River to the north, Mount Song to the west, and the vast Huanghuai Plain to the 
southeast. Moreover, the dominant wind in winter is the northwest wind, which is blocked by the surrounding Taihang Mountain and Songshan Mountain, resulting pollutants do not disperse easily. In addition, as of December 2017, the number of motor vehicles in Zhengzhou has reached 3.4711 million, there is serious pollution from automobile exhaust. Zhengzhou's central heating season, which runs from mid-November to mid-March, is dominated by coal-fired heating, which is a major cause of the city's heavy pollution during winter and spring. These factors combine to result a range of health-damaging pollutants accumulate and deposit over the urban area, making Zhengzhou become one of the most worst air polluted area for China ${ }^{19,20}$.

\subsection{Data gathering}

Daily data of clinic visits were obtained from The First Affiliated Hospital of Henan University of Chinese Medicine, between October 28, 2013 and May 1, 2018, including the patients' ID, gender, age, and date of diagnosis. The name of upper respiratory tract infection (URTI) was standardized with the International Classification of Diseases (ICD-10) 10th Edition Code (J06.902-J06.903). The Mysql software was used to categorized, screened, and summarized the patients' medical records according to daily different diseases. The URTI outpatients were stratified by gender (female and male) and age (adolescents: aged 0-18 years; adults: aged 19-59 years; elderly: aged $\geq 60$ years).

The data of the air pollutants $\left(\mathrm{PM}_{2.5}, \mathrm{PM}_{10}, \mathrm{SO}_{2}, \mathrm{NO}_{2}, \mathrm{CO}\right.$ and $\left.\mathrm{O}_{3}\right)$ of Zhengzhou city, from October 28, 2013 to May 1, 2018, were collected from the website: Tianqihoubao ${ }^{21}$. $\mathrm{PM}_{2.5}, \mathrm{PM}_{10}, \mathrm{SO}_{2}, \mathrm{NO}_{2}, \mathrm{CO}$ were reported with 24-h averaged concentrations, and $\mathrm{O}_{3}$ with 8h mean concentrations.

The influence of meteorological factors were taken into consideration, and those data were obtained from the website: Weather Underground ${ }^{22}$. In this study, daily mean temperature, relative humidity, and wind speed were used.

\subsection{Analyzed statistically}

Using the SPSS 22.0 software to statistically describe daily clinic visits for URTI, meteorological factors and air pollution levels, and Spearman rank correlation analysis was performed for the detections of the relationships between air pollutions, URTI outpatients and meteorological conditions.

Using Poisson distribution to analyze statistically the daily outpatient visits for URTI. Meanwhile, the relationship of air pollutions and incidence of a respiratory system diseases was non-linear, and respiratory illness changed with lagged effects of air pollutants levels ${ }^{23}$. Therefore, adopting the quasi-Poisson regression with a distributed lag non-linear model (DLNM) to research the effect of air pollutants on URTI outpatients. The impact of secular trends, seasonality and weekends were controlled, and the relationship between air pollutions and URTI outpatients were matched. Take the daily mean temperature as the meteorological indicator and relative humidity was controlled. The two dimensions of predictor and lags were conducted to study air pollutants on URTI outpatient visits. Take the average of each index as the reference level, and $15 \mathrm{~d}$ is the maximum lag period. The reference model was used in the calculations as follows 24 :

$$
\begin{gathered}
\log \left[E\left(Y_{i}\right)\right]=\alpha+N S\left(\text { time }_{t}\right)+N S\left(\text { hum }_{i}, d f\right)+N S\left(\text { wind }_{i}, d f\right) \\
+\sum_{j=1}^{m} w_{j}\left(\text { strata }_{j t}\right)+\beta T_{t, l 1}+\gamma \text { pollution }_{t, l}+\xi
\end{gathered}
$$

In the model, $E\left(Y_{i}\right)$, the number of URTI outpatients on day i; NS(time $)$, the natural cubic spline of the time (date) $t, d f$ (degree of freedom) $=7 /$ year; hum $_{i}$ the mean relative humidity on day $i, d f=3$; wind $_{i}$ the wind speed at day $i, d f=3$; $w_{j}$, the regression coefficient of variable; strata $_{j t}$ the dummy variable of the week and month (such as public holidays and weekends) effects; l, days of lag, with a maximum lag of 15 days; $\beta T_{t r h}$, the temperature matrix with a lag of I-day obtained by DLNM with a coefficient of $\beta ; \gamma, \gamma$ Pollution ${ }_{t / 2}$, the Pollution ( $\mathrm{PM}_{2.5}, \mathrm{PM}_{10}, \mathrm{SO}_{2}, \mathrm{NO}_{2}, \mathrm{CO}$, and $\mathrm{O}_{3}$ ) matrix with a lag of I-day obtained by DLNM with a coefficient of $\gamma^{25-27}$. $\xi$ and $a$ represent the residual and the intercept, respectively.

In addition, the relative risk (RR) of the lag effects and the cumulative effects of $10 \mu \mathrm{g} / \mathrm{m}^{3}$ increment of each pollutant on the URTI outpatients were calculated with the R 3.6.1 software. All data analyses were carried out using R3.6.1 software. Using the "dlnm" package to fit DLNM. 


\section{Results}

\subsection{Description of the general condition}

Summarizing the distribution of daily URTI outpatients, concentrations of air pollutants and factors of meteorology in Table 1. A total of 475013 cases of URTI outpatients was obtained, with a female-to male- ratio of 1:1.13. The distribution of daily URTI outpatients fluxed with mean air pollutant concentrations during the period were presented in Fig. 1, with obvious seasonal fluctuations, and were higher in $\mathrm{cool} / \mathrm{cold}$ season and lower in warm season relatively. Concentration of $\mathrm{O}_{3}$ level showed opposite trend of fluctuations in cool/cold and warm seasons.

As shown in Table 2, daily URTI outpatient visits were positively related to $\mathrm{PM}_{2.5}, \mathrm{PM}_{10}, \mathrm{SO}_{2}, \mathrm{NO}_{2}$ and $\mathrm{CO}$ concentrations, especially $\mathrm{NO}_{2}$ $(r=0.362, P<0.01)$, while were negatively related to temperature, relative humidity, wind speed and $\mathrm{O}_{3}$. Temperature, relative humidity, wind speed and each air pollutants were significantly correlated, especially the correlation of $\mathrm{PM}_{10}$ and $\mathrm{PM}_{2.5}(\mathrm{r}=0.872, P<0.01)$.

Table 1

Analyzed characteristics of daily URTI outpatient visits, meteorological factors, and air pollutants in Zhengzhou during 2013.10.28 - 2018.5.1.

\begin{tabular}{|c|c|c|c|c|c|}
\hline Variables & No. of days & No. of cases (\%) & Daily visits no. $(\overline{\mathrm{x}} \pm \mathrm{s})$ & Minimum cases & Maximum cases \\
\hline \multicolumn{6}{|l|}{ URTI outpatient visits } \\
\hline Total & 1677 & $475013(100 \%)$ & $283 \pm 99$ & 87 & 838 \\
\hline \multicolumn{6}{|l|}{ Gender } \\
\hline Male & 1677 & $252431(53.14 \%)$ & $150 \pm 51$ & 38 & 440 \\
\hline Female & 1677 & $222582(46.86 \%)$ & $132 \pm 49$ & 12 & 398 \\
\hline \multicolumn{6}{|l|}{ Age } \\
\hline$\leq 18$ & 1677 & $298879(62.92 \%)$ & $178 \pm 58$ & 51 & 458 \\
\hline $19-59$ & 1677 & 159344(33.55\%) & $95 \pm 44$ & 18 & 376 \\
\hline$\geq 60$ & 1677 & $16790(3.53 \%)$ & $10 \pm 6$ & 0 & 43 \\
\hline \multicolumn{6}{|l|}{ Meteorological factors } \\
\hline Temperature $\left({ }^{\circ} \mathrm{C}\right)$ & 1677 & / & $14.98 \pm 9.58$ & -6.30 & 33.10 \\
\hline Relative humidity (\%) & 1677 & / & $65.52 \pm 19.19$ & 14 & 100 \\
\hline Wind(m/s) & 1677 & / & $10.20 \pm 4.36$ & 3.7 & 31.30 \\
\hline \multicolumn{6}{|l|}{ Air pollutants } \\
\hline $\mathrm{PM}_{2.5}\left(\mu \mathrm{g} / \mathrm{m}^{3}\right)$ & 1677 & / & $83.20 \pm 61.04$ & 10 & 604 \\
\hline $\mathrm{PM}_{10}\left(\mu \mathrm{g} / \mathrm{m}^{3}\right)$ & 1677 & / & $147.19 \pm 79.53$ & 10 & 677 \\
\hline $\mathrm{SO}_{2}\left(\mu \mathrm{g} / \mathrm{m}^{3}\right)$ & 1677 & / & $31.30 \pm 25.77$ & 2 & 203 \\
\hline $\mathrm{NO}_{2}\left(\mu \mathrm{g} / \mathrm{m}^{3}\right)$ & 1677 & / & $51.95 \pm 19.30$ & 15 & 156 \\
\hline $\mathrm{CO}\left(\mu \mathrm{g} / \mathrm{m}^{3}\right)$ & 1677 & / & $1523.8 \pm 708.8$ & 490 & 6080 \\
\hline $\mathrm{O}_{3}\left(\mu \mathrm{g} / \mathrm{m}^{3}\right)$ & 1677 & / & $55.74 \pm 33.11$ & 3 & 177 \\
\hline
\end{tabular}

Table 2

Analyzed the correlation of meteorological factors, air pollutions and URTI outpatient visits in Zhengzhou during 2013.10.28 - 2018.5.1 


\begin{tabular}{|c|c|c|c|c|c|c|c|c|c|c|}
\hline & \multirow{2}{*}{$\begin{array}{l}\text { URTI } \\
\text { outpatient } \\
\text { visits }\end{array}$} & \multicolumn{3}{|c|}{ Meteorological factors } & \multicolumn{6}{|c|}{ Air pollutants } \\
\hline & & $\begin{array}{l}\text { T mean } \\
\left({ }^{\circ} \mathrm{C}\right)\end{array}$ & $\begin{array}{l}\text { Humidity } \\
(\%)\end{array}$ & $\begin{array}{l}\text { Wind } \\
(\mathrm{m} / \mathrm{s})\end{array}$ & $\begin{array}{l}\mathrm{PM}_{2.5} \\
\left(\mu \mathrm{g} / \mathrm{m}^{3}\right)\end{array}$ & $\begin{array}{l}\mathrm{PM}_{10} \\
\left(\mu \mathrm{g} / \mathrm{m}^{3}\right)\end{array}$ & $\begin{array}{l}\mathrm{SO}_{2} \\
\left(\mu \mathrm{g} / \mathrm{m}^{3}\right)\end{array}$ & $\begin{array}{l}\mathrm{NO}_{2} \\
\left(\mu \mathrm{g} / \mathrm{m}^{3}\right)\end{array}$ & $\begin{array}{l}\text { CO } \\
\left(\mu \mathrm{g} / \mathrm{m}^{3}\right)\end{array}$ & $\begin{array}{l}\mathrm{O}_{3} \\
\left(\mu \mathrm{g} / \mathrm{m}^{3}\right)\end{array}$ \\
\hline $\begin{array}{l}\text { URTI } \\
\text { outpatient } \\
\text { visits }\end{array}$ & 1 & & & & & & & & & \\
\hline \multicolumn{11}{|l|}{$\begin{array}{l}\text { Meteorological } \\
\text { factors }\end{array}$} \\
\hline $\mathrm{T}$ mean $\left({ }^{\circ} \mathrm{C}\right)$ & $-0.367^{\star \star}$ & 1 & & & & & & & & \\
\hline Humidity (\%) & $-0.203^{\star \star}$ & $0.106^{\star \star}$ & 1 & & & & & & & \\
\hline Wind (m/s) & -0.11 & $-0.123^{\star}$ & $-0.277^{\star \star}$ & 1 & & & & & & \\
\hline \multicolumn{11}{|l|}{ Air pollutions } \\
\hline $\mathrm{PM}_{2.5}\left(\mu \mathrm{g} / \mathrm{m}^{3}\right)$ & $0.183^{\star \star}$ & $-0.403^{\star \star}$ & $0.197^{\star \star}$ & $-0.230^{\star \star}$ & 1 & & & & & \\
\hline $\mathrm{PM}_{10}\left(\mu \mathrm{g} / \mathrm{m}^{3}\right)$ & $0.167^{\star \star}$ & $-0.294^{\star \star}$ & -0.029 & $-0.174^{\star *}$ & $0.872^{\star \star}$ & 1 & & & & \\
\hline $\mathrm{SO}_{2}\left(\mu \mathrm{g} / \mathrm{m}^{3}\right)$ & $0.240^{\star \star}$ & $-0.492^{\star \star}$ & $-0.215^{\star \star}$ & $-0.092^{\star \star}$ & $0.444^{\star \star}$ & $0.475^{\star \star}$ & 1 & & & \\
\hline $\mathrm{NO}_{2}\left(\mu \mathrm{g} / \mathrm{m}^{3}\right)$ & $0.362^{\star \star}$ & $-0.385^{\star \star}$ & -0.003 & $-0.447^{\star *}$ & $0.671^{\star \star}$ & $0.696^{\star *}$ & $0.621^{\star \star}$ & 1 & & \\
\hline $\mathrm{CO}\left(\mu \mathrm{g} / \mathrm{m}^{3}\right)$ & $0.163^{* *}$ & $-0.451^{* *}$ & $0.224^{* \star}$ & $-0.145^{\star *}$ & $0.772^{\star \star}$ & $0.646^{* *}$ & $0.649^{* \star}$ & $0.604^{\star *}$ & 1 & \\
\hline $\mathrm{O}_{3}\left(\mu \mathrm{g} / \mathrm{m}^{3}\right)$ & $-0.284^{\star \star}$ & $-0.734^{\star \star}$ & $-0.168^{\star \star}$ & -0.034 & $-0.390^{\star *}$ & $-0.281^{\star \star}$ & $-0.523^{\star \star}$ & $-0.467^{\star *}$ & $-0.509^{* \star}$ & 1 \\
\hline
\end{tabular}

\subsection{Model fitting analysis results.}

Figure 2 showed that $\mathrm{PM}_{2.5}, \mathrm{PM}_{10}, \mathrm{NO}_{2}$ and $\mathrm{CO}$ had similar effective trends on $\mathrm{RR}$ in total data set, and female, male, adolescent, adult, and elderly sub-groups. The risk effects were shown on lag day 0 , implying an immediately effects, and $\mathrm{PM}_{10}, \mathrm{NO}_{2}$ reached greatest risk on lag 0 , while the peak risk of $\mathrm{PM}_{2.5}$ and $\mathrm{CO}$ showed on lag 15. The higher concentrations of $\mathrm{PM}_{2.5}, \mathrm{PM}_{10}, \mathrm{NO}_{2}$ and $\mathrm{CO}$, the greater RR value, but the increases were nonlinear. SO2 showed similar effects on URTI outpatient visits in the total data set, and female, male, adolescent, and adult sub-groups, and reached a maximum on lag 0 , with immediately effects. Subsequently, the RR decreased gradually and became insignificant statistically. On the contrary, for the elderly group, the impact reached the maximum on lag 15 days, with $\mathrm{RR}$ value increased with $\mathrm{SO}_{2}$ concentrations. At high concentration levels, the risks of $\mathrm{O}_{3}$ didn't show statistical significance.

Figure 3 showed the RR trend of URTI outpatient visits on every $10 \mu \mathrm{g} / \mathrm{m}^{3}$ increase in air pollutants concentrations in different genders and age sub-groups during lag days $0-15$. For $\mathrm{PM}_{2.5}, \mathrm{PM}_{10}, \mathrm{SO}_{2}, \mathrm{NO}_{2}$ and $\mathrm{CO}$, there were similar effective trends in the total data set, female, male, adolescent, adult, and elderly sub-groups, with the risk effects on lag 0 day, especially for $\mathrm{PM}_{10}, \mathrm{SO}_{2}$ and $\mathrm{NO}_{2}$ reached greatest risk on lag 0 [RR $\mathrm{RR}_{\mathrm{PM} 10}: 1.001195 \% \mathrm{Cl}(1.0002-1.0020) ; \mathrm{RR}_{\mathrm{SO} 2}: 1.008495 \% \mathrm{Cl}(1.0019-1.0130) ; \mathrm{RR}_{\mathrm{NO} 2}: 1.014995 \% \mathrm{Cl}(1.0111-$ 1.0188), respectively], while the risk effect of $\mathrm{PM}_{10}$ was insignificant in the adults and elderly group and $\mathrm{SO}_{2}$ was insignificant in the elderly group. The peak risk of $\mathrm{PM}_{2.5}$ and $\mathrm{CO}$ showed on at least lag 15 days $\left[\mathrm{RR}_{\mathrm{PM} 2.5}, 1.001495 \% \mathrm{Cl}(1.0003-1.0025) ; \mathrm{RR}_{\mathrm{CO}}, 1.0002\right.$ $95 \% \mathrm{Cl}(1.0001-1.0003)$, respectively]. Except the adult group and elderly group in $\mathrm{PM}_{2.5}$ reached greatest risk on lag 12 and 14 , respectively [RR adult: $1.000795 \% \mathrm{Cl}(1.0000-1.0014) ; R_{\text {elderly: }} 1.001395 \% \mathrm{Cl}(1.0002-1.0025)$, respectively]. And the influence of $\mathrm{CO}$ in the elderly group reached the maximum on lag 13 days [RR $\left.\mathrm{R}_{\text {elderly, }} 1.000195 \% \mathrm{Cl}(1.0000-1.0002)\right]$. 
Summarizing the cumulative relative risk impacts of different air pollutants on different subgroups of outpatients with URTI within the lag period in Table S1. The influencing effects of $\mathrm{PM}_{10}, \mathrm{SO}_{2}$ and $\mathrm{NO}_{2}$ was greater in female than male, and greater in the adolescents and elderly than in adults. For $\mathrm{PM}_{10}$, the accumulated effects of lag 0 to lag $0-12$ and lag 0-14 to lag 0-15 days in females, and lag 0 to lag $0-12$ days in male subgroups showed statistical significance, reached the peak value on lag $0-15$ and lag $0-1$ days, respectively [RR female: $1.0044,95 \% \mathrm{Cl}(1.0005-1.0082) ; R_{\text {male }}: 1.0020,95 \% \mathrm{Cl}(0.9982-1.0058)$, respectively], while cumulative risks of $\mathrm{PM}_{10}$ on adults and elderly subgroups were not statistically significant. $\mathrm{NO}_{2}$ caused cumulative effects were significant on the incidence risk in females, males, adolescents, adults, and elderly subgroups during lag 0-15 days, and had greatest influences on lag 0-15 days, except the elderly subgroup on lag $0-14$ days $\left[\mathrm{RR}_{\text {female }}: 1.0683,95 \% \mathrm{Cl}(1.0518-1.0850) ; \mathrm{RR}_{\text {male }}: 1.0569,95 \% \mathrm{Cl}(1.0407-1.0733)\right.$; $\mathrm{RR}_{\text {adolescent }}$ :

$1.0716,95 \% \mathrm{Cl}(1.0555-1.0878) ; R_{\text {adult }}: 1.0480,95 \% \mathrm{Cl}(1.0278-1.0687) ; R_{\text {elderly }}: 1.0504,95 \% \mathrm{Cl}(1.0191-1.0826)$, respectively]. For $\mathrm{SO}_{2}$, statistical significance of cumulative effect was observed in the lag 0 to lag $0-3$ days, with the maximum effect in lag $0-1$ day in the males, adolescents, and adults $\left[\mathrm{RR}_{\text {male }}: 1.0117,95 \% \mathrm{Cl}(1.0049-1.0186) ; \mathrm{RR}_{\text {adolescent }}: 1.0120,95 \% \mathrm{Cl}(1.0053-1.0188) ; R_{\text {adult }}\right.$ : $1.0108,95 \% \mathrm{Cl}(1.0022-1.0194)$, respectively], while in the female, the maximum effect occurred on was in lag $0-2\left[\mathrm{RR}_{\text {female }}: 1.0117\right.$, $95 \% \mathrm{Cl}(1.0037-1.0197)]$. Furthermore, the accumulated risks of $\mathrm{SO}_{2}$ on elderly was not statistically significant. The entire cumulative influence of a 10-unit increases in $\mathrm{CO}$ during 15 days of lag was significant on the incidence risk in females, males, adolescent during lag 0 to lag $0-1$ days, and in adult, it was in lag 0 to lag $0-3$ days, and got the peak value on lag days $0-1\left[\mathrm{RR}_{\text {female: }}: 1.0001,95 \% \mathrm{Cl}\right.$ (1.0000-1.0003); $\mathrm{RR}_{\text {male }}: 1.0002,95 \% \mathrm{Cl}(1.0000-1.0004) ; \mathrm{RR}_{\text {adolescent }}: 1.0002,95 \% \mathrm{Cl}(1.0000-1.0003) ; \mathrm{RR}_{\text {adult }}: 1.0002,95 \% \mathrm{Cl}(1.0000$ 1.0004) respectively], while there was no significance in elderly. The cumulative risks of $\mathrm{PM}_{2.5}$ and $\mathrm{O}_{3}$ didn't show statistical significance.

\section{Discussion}

For URTI, the result of this study identified that $\mathrm{PM}_{10}, \mathrm{SO}_{2}, \mathrm{NO}_{2}$ and $\mathrm{CO}$ have strong immediate and lag cumulative effects in the females, adolescents, and elderly. $\mathrm{PM}_{2.5}$ has lag effects but has no significant lag cumulative impact effects on gender and age.

Original studies were rare for URTI. A study from Zhang Ying ${ }^{12}$ demonstrated that the influence of air pollution on URTI was more obvious than lower respiratory tract infections. Findings of this study implied that it's necessary to explore the association between URTI and air pollutions with more time series studies. The current study investigated the relationship between ambient air pollutants and outpatient visits of URTI in Zhengzhou, China, from October 28, 2013 and May 1, 2018. We found that average annual PM $2.5\left(83 \mu \mathrm{g} / \mathrm{m}^{3}\right)$, $\mathrm{PM}_{10}\left(147 \mu \mathrm{g} / \mathrm{m}^{3}\right)$, and $\mathrm{NO}_{2}\left(52 \mu \mathrm{g} / \mathrm{m}^{3}\right)$ concentrations were higher than the ambient air quality secondary standard (GB3095-2012) in china, and $\mathrm{PM}_{2.5}, \mathrm{PM}_{10}, \mathrm{SO}_{2}, \mathrm{NO}_{2}, \mathrm{CO}$ were positive related to clinical visits for URTI, especially $\mathrm{NO}_{2}(\mathrm{r}=0.362, P<0.01)$. For each 10 $\mu \mathrm{g} / \mathrm{m}^{3}$ increase, $\mathrm{PM}_{10}, \mathrm{SO}_{2}, \mathrm{NO}_{2}$ had the maximum effects at lag day 0 [RR $\mathrm{PM}_{10}: 1.0011,95 \% \mathrm{Cl}:(1.0002-1.0020) ; \mathrm{RR}_{\mathrm{SO} 2}: 1.0084,95 \% \mathrm{Cl}$ : (1.0039-1.0130); $\mathrm{RR}_{\mathrm{NO} 2}: 1.0149,95 \% \mathrm{Cl}:(1.0111-1.0188)$, respectively], while $\mathrm{PM}_{2.5}$ and $\mathrm{CO}$ had highest risks on lag 15 day $\left[\mathrm{RR}_{\mathrm{PM} 2.5}\right.$ : 1.0014, 95\% Cl: (1.0003-1.0025); $\mathrm{RR}_{\mathrm{CO}}: 1.1851,95 \% \mathrm{Cl}$ : (1.0525-1.3344), respectively]. The risks of $\mathrm{O}_{3}$ didn't show statistical significance.

This research is consistent with other parts of China, such as Beijing, Shenyang, Lanzhou, etc. Especially, in Shenyang ${ }^{28}$, which reported that exposure to ambient $\mathrm{PM}_{2.5}, \mathrm{PM}_{10}, \mathrm{SO}_{2}, \mathrm{NO}_{2}, \mathrm{CO}$ had statistical significant relations with outpatient visits for URTI, within the optimal lag period, when concentrations of $\mathrm{PM}_{10}, \mathrm{PM}_{2.5}, \mathrm{SO}_{2}, \mathrm{NO}_{2}, \mathrm{CO}$ increased each $10 \mu \mathrm{g} / \mathrm{m}^{3}$ [RR $\mathrm{PM10}$ 1.002, 95\%Cl: (1.00011.0004); $\operatorname{RR}_{\mathrm{PM} 2.5} 1.0014,95 \% \mathrm{Cl}$ : (1.0000-1.0030); $\mathrm{RR}_{\mathrm{SO} 2}$ : 1.0032, 95\%Cl: (1.0017-1.0047); $\mathrm{RR}_{\mathrm{NO} 2}: 1.0086,95 \% \mathrm{Cl}$ : (1.0037-1.0130); $\mathrm{RR}_{\mathrm{CO}}: 1.1900,95 \% \mathrm{Cl}$ : (1.0879-1.3212), respectively)]. $\mathrm{O}_{3}$ exposure was reported positive associated with URTI in some reports ${ }^{29,30}$, but not all previous studies. Our study found that increased $\mathrm{O}_{3}$ level was unrelated with outpatient visits of URTI. Probable reasons for this difference may include different $\mathrm{O}_{3}$ concentrations along with different climate temperatures in different regions. The $\mathrm{O}_{3}$ pollution was more obvious in the summer days.

Alternatively, $\mathrm{O} 3$ and other air pollutants interactions may result in no significant impact on outpatients with URTI ${ }^{14}$. Similarly, a study conducted in Beijing, found that the increases in concentrations of $\mathrm{PM}_{10}, \mathrm{SO}_{2}$, and $\mathrm{NO}_{2}$ by per $10 \mu \mathrm{g} / \mathrm{m}^{3}$ had significant impacts on daily URTI outpatient visitors [RR PM10 $_{1}$ 1.0113, 95\% Cl: (1.0049-1.0173); $\mathrm{RR}_{\mathrm{SO} 2}: 1.0114,95 \mathrm{Cl}$ : (1.0077-1.0183); $\mathrm{RR}_{\mathrm{N} 02}: 1.0213,95 \% \mathrm{Cl}$ : (1.0150-1.0213), respectively)]. The RR-values were higher in Zhengzhou than those reported in Shenyang, but lower than Beijing. Moreover, study indicated that different pollutants in different areas had different strongest-effect-lag-time for the same disease and their corresponding RR-values, which might be considered to the human susceptibility and regional pollutants with significant regional 
characteristics ${ }^{31}$. More studies have been done in the north China than in the south, due to the worse air quality in the north China ${ }^{32}$, which was contributed by heavy industrial emission and heating season coal consuming, and also related to the local geographical environment, economic development, energy structure, air pollutions control and weather conditions ${ }^{33}$.

In the past few years, the levels of particulate matters $\left(\mathrm{PM}_{10}, \mathrm{PM}_{2.5}\right)$ in Zhengzhou were exceeding the national secondary maximum contaminant level, and $\mathrm{NO}_{2}$ was 1.3 times higher than the national standard, while $\mathrm{SO}_{2}, \mathrm{CO}, \mathrm{O}_{3}$ approached the national secondary maximum contaminant level. Coal burning contributed significantly to $\mathrm{PM}_{2.5}, \mathrm{PM}_{10}$ and $\mathrm{SO}_{2}$ pollution, especially in winter ${ }^{34}$. $\mathrm{NO}_{2}$ is mainly emitted into the air by burning fossil fuels, especially vehicle fuels. $\mathrm{O}_{3}$ is formed by the interaction of nitrogen oxides (NOx) and volatile organic compounds (VOCs) with sunlight and it is also high positive correlation with vehicles exhaust emissions ${ }^{35}$. Using gasoline or diesel fuel cars and using carbon compounds in industrial processes are the major two responsibilities for $\mathrm{CO}$ being discharged to the atmosphere 36,37 .

$\mathrm{PM}_{10}$ and $\mathrm{PM}_{2.5}$ are mainly deposited on the trachea, especially $\mathrm{PM}_{2.5}$ has a huge surface area and adsorbs various toxic and harmful substances, and can enter into the terminal bronchioles and alveoli ${ }^{38}$, leading to a series of lung injuries including destruction of the airway epithelial barrier, interfered cellular signaling pathways, destroyed lung parenchyma, cell immunity, epigenetic modifications and autophagy ${ }^{39}$. Reports demonstrated that exposed to high-level $\mathrm{SO}_{2}$ had irritative effects on the smooth muscle of the respiratory tract, causing bronchoconstriction and inflammation of the upper airway, increase airway resistance, and decrease lung function ${ }^{40,41}$. $\mathrm{NO}_{2}$ is also regarded as a kind of respiratory tract irritation. Animal and human exposure studies have found that inhalation of $\mathrm{NO}_{2}$ mainly invaded in the distal bronchioalveolar and the alveoli, causing respiratory tract infections and promoting lung inflammation ${ }^{42}$. $\mathrm{O}_{3}$, as a strong corrosive substance, can cause adverse effects on the respiratory system through inflammation, oxidative stress, airway hyperresponsiveness, DNA damage, and another mechanism causing and aggravating pulmonary disease ${ }^{43}$. Acute and long-term exposure to high-level $\mathrm{CO}$ in enclosed spaces can cause serious health hazards to humans, including death, while number of studies found that associations between low-level $\mathrm{CO}$ and beneficial in pulmonary health ${ }^{44,45}$.

The influences of air pollutants on health are complex and vary with different genders, ages, and other risk factors.

From the gender perspective, most studies have discovered that females were more vulnerable to pollutants than males. In this study,

We also found that calculating the overall cumulative risks of PM10, SO2, and NO2 concentrations increasing by $10 \mu \mathrm{g} / \mathrm{m} 3$, lagging 15 days, females were significantly higher than males. It indicated that female was more susceptible and threatened potentially by pollutants. However, some studies suggested contrary view, in which males were more susceptible to particulate $\operatorname{matter}_{(}\left(\mathrm{PM}_{2.5}, \mathrm{PM}_{10}\right)$ exposures than females ${ }^{29,46}$. There were also studies that showed that in Arak city of Iran, $\mathrm{PM}_{2.5}, \mathrm{PM}_{10}, \mathrm{SO}_{2}, \mathrm{NO}_{2}$ and $\mathrm{CO}$ had significantly higher influence on the hospitalization of males with respiratory diseases than that of females, and there was no gender difference in the influence on the hospitalization of circulatory disease ${ }^{47,48}$. The differences in lung growth rates and function decrease between men and women may influence the incidence of respiratory inflammation ${ }^{49,50}$. In addition, particulate matter was deposited in women's lungs more than in men, which making them more susceptible to respiratory disease ${ }^{42,51}$. Complexity was reflected in the actual exposure environment, occupation characteristics, smoking behavior, education level and ethnicity of different gender population, which impacted the health effects of air pollutant exposure ${ }^{52}$. Such as both active and passive smoking can lead to a decline in lung function, especially in small airway, moreover, the decline in lung function of active smoking people was more serious than passive smoking ${ }^{53}$. Therefore, the impact of air pollution on gender differences still needs to be further studied.

From the perspective of age, adolescents and elderly groups were more vulnerable to air pollutants than in adults aged 19-59 years old.

In this study, the total cumulative effect of each pollutant increased by $10 \mu \mathrm{g} / \mathrm{m}^{3}$ was calculated, the incidence of URTI outpatient visits were different in different age groups. For $\mathrm{PM}_{10}, \mathrm{SO}_{2}$ and $\mathrm{NO}_{2}$, the risk effects were greater in the adolescents (aged $\leq 18$ years old) than in adults (aged 19-59 years old), while for the effect of $\mathrm{CO}$ was greater in the adolescents and adults than in the elderly. It indicated that elderly and adolescents were more susceptible to air pollutants than adults, except $\mathrm{CO}$ exposure. These results were consistent to previous studies. Li reported that exposed by air pollution in short-term was related to increased risk of URTI for aged 0-14 years old in Hefei ${ }^{14}$. A study from Beijing indicated that the elder more than 65 years old was the most sensitive to air pollution, followed by adolescents younger than 14 years old ${ }^{54}$. There are two reasons for the above phenomenon: firstly, compared with adults, adolescents' lungs and immune system are not mature, which were susceptible to air pollutions and adolescents tend to spend more time doing 
intense outdoors activities, so they may breathe a higher amount of outdoor air pollutants ${ }^{55,56}$; secondly, for the elderly, both physical function and physical activity had been on a downward trend, showing a decline in the ability of the immune system to fight against exogenous hazards, as well as the cumulative effect caused by long-term exposed from air pollutants, making the elderly more susceptible to air pollutants ${ }^{57}$. It also implied that the health effects of air pollutant exposure in different age groups were related to the actual exposure level, the sensitivity of pollutant exposure (long-term exposure to pollutants reduces sensitivity to pollutants, people in clean air environment were more sensitive), and the physiological characteristics of aging ${ }^{58,59}$.

However, there were several limitations in this study: 1) due to the interaction of the pollutants, there was bias to evaluate the risk effects of each single pollutant; 2) the risk effects of indoor pollutants were not controlled; 3 ) the impacts of individual living habits and occupations on URTI were not considered.

\section{Conclusions}

Our results indicated that $\mathrm{PM}_{10}, \mathrm{SO}_{2}, \mathrm{NO}_{2}$ and $\mathrm{CO}$ have strong immediate and lag cumulative effects in the females, adolescents, and elderly. $\mathrm{PM}_{2.5}$ has lag effects but has no significant lag cumulative impact effects on gender and age.

\section{Abbreviations}

URTI

Upper respiratory tract infection

DLNM

Distributed lag non-linear model

Adolescents

aged $0-18$ years

Elderly

aged $\geq 60$ years

Adults

aged $19-59$ years

\section{Declarations}

\section{Ethics approval and consent to participate}

Not applicable.

\section{Consent for publication}

Not applicable.

\section{Availability of data and materials}

The datasets used and/or analyzed during the current study are available from the corresponding author on reasonable request.

\section{Competing interests}

We declare no competing interests.

\section{Funding}

This study was supported by the National Natural Science Foundation of China (No. 8207152870 and No. 8167140938 ), the Traditional Chinese Medicine Discipline Construction Project of Henan Province (No. STG-ZYXKY-2020014) and the Traditional Chinese Medicine Scientific Research Special Project of Henan Province (No. 20-21ZY1019).

\section{Authors' contributions}

Shanshan Lin: Software, Model analysis, Visualization, Writing - Original Draft. 
Huihui He: Software, Contributed important valuable comments.

Rui Jia, Juan Du: Software, Analyzed the data.

Ningyi Ma: Collected the air pollutant data.

Mengdan Qian, Yan Wang: Collated the air pollutant data.

Huimin Huang, Deqi Kong: Processed the hospital data.

Ya Li: Review \& Editing.

All the authors read the paper, offered interpretation, and provided comments on the final the draft of manuscript.

\section{Acknowledgements}

This study was supported by the National Natural Science Foundation of China (No.8207152870 and No.8167140938), the Traditional Chinese Medicine Discipline Construction Project of Henan Province(No.STG-ZYXKY-2020014) and the Traditional Chinese Medicine Scientific Research Special Project of Henan Province(No.20-21ZY1019). We thank Ms. Ruihong Wu and Mr. Pengyong Dong in the IT department in the Hospital for their assistants in data collecting of dailyoutpatient visits.

\section{References}

1. Ten threats to global health in 2019. https://www.paho.org/en/news/17-1-2019-ten-threats-global-health-2019 (accessed 6 October 2020).

2. Tetyana POL, Olena C, Maksim P. Environmental Performance Index: relation between social and economic welfare of the countries. 2018; 9(3): 1-11.

3. Brook RD, Rajagopalan S, Pope CA 3rd, Brook JR, Bhatnagar A, Diez-Roux AV, Holguin F, Hong Y, Luepker RV, Mittleman MA, Peters A, Siscovick D, Smith SC Jr, Whitsel L, Kaufman JD. \& American Heart Association Council on Epidemiology and Prevention, Council on the Kidney in Cardiovascular Disease, and Council on Nutrition, Physical Activity and Metabolism. Particulate matter air pollution and cardiovascular disease: An update to the scientific statement from the American Heart Association. 2010 121(21): $2331-78$.

4. Song C, Wu L, Xie Y, He J, Chen X, Wang T, Lin Y, Jin T, Wang A, Liu Y, Dai Q, Liu B, Wang YN, Mao H. Air pollution in China: Status and spatiotemporal variations. 2017; 227.

5. Kurt OK, Zhang J, Pinkerton KE. Pulmonary health effects of air pollution. Curr Opin Pulm Med. 2016;22(2):138-43.

6. Mannucci PM, Franchini M. Health Effects of Ambient Air Pollution in Developing Countries. Int J Environ Res Public Health. 2017;14(9):1048.

7. Grief SN. Upper respiratory infections. Prim Care. 2013;40(3):757-70.

8. Lo YY, Lam CL, Mercer SW, et al. Patient morbidity and management patterns of community-based primary health care services in Hong Kong. Hong Kong Med J. 2011;17(3 Suppl 3):33-7.

9. Bono R, Romanazzi V, Bellisario V, et al. Air pollution, aeroallergens and admissions to pediatric emergency room for respiratory reasons in Turin, northwestern Italy. BMC Public Health. 2016;16:722.

10. Rayroux C, Gasche-Soccal P, Janssens JP. [Air pollution and its impact on the respiratory system]. Rev Med Suisse. 2020;16(715):2211-6.

11. Wang C, Feng L, Chen K. The impact of ambient particulate matter on hospital outpatient visits for respiratory and circulatory system disease in an urban Chinese population. Sci Total Environ. 2019;666:672-9.

12. Zhang YNG, Kang Y, Shang Z, Wang S, Li X, Wang Y. Time-series analysis of the association between outdoor air pollution and emergency room admissions for respiratory diseases in Beijing City. Journal of Lanzhou University. 2015;51(1):87-92.

13. Wei J. The characteristics of air pollution in shenyang and the analysis of the hysteresis effect on respiratory diseases [a master's degree thesis]: China medical university 2018.

14. Li YR, Xiao CC, Li J, et al. Association between air pollution and upper respiratory tract infection in hospital outpatients aged $0-14$ years in Hefei, China: a time series study. Public Health. 2018;156:92-100. 
15. Zhang Z, Wang J, Chen L, et al. Impact of haze and air pollution-related hazards on hospital admissions in Guangzhou, China. Environ Sci Pollut Res Int. 2014;21(6):4236-44.

16. Tam WW, Wong TW, Ng L, Wong SY, Kung KK, Wong AH. Association between air pollution and general outpatient clinic consultations for upper respiratory tract infections in Hong Kong. PLoS One. 2014;9(1):e86913.

17. Lin YK, Chang CK, Chang SC, Chen PS, Lin C, Wang YC. Temperature, nitrogen dioxide, circulating respiratory viruses and acute upper respiratory infections among children in Taipei, Taiwan: a population-based study. Environ Res. 2013;120:109-18.

18. Zhang F, Zhang H, Wu C, et al. Acute effects of ambient air pollution on clinic visits of college students for upper respiratory tract infection in Wuhan, China. Environ Sci Pollut Res Int 2021.

19. Xu R. Research on the Policy of Motor Vehicle Restriction in Zhengzhou [a master's degree thesis]: Zhengzhou University; 2019.

20. Liu Y. Study on Local Government Responsibility in Air Pollution Control -Take Zhengzhou City, Henan Province as an example [a master's degree thesis]: Henan University; 2020.

21. Zhengzhou Air Quality Index. http://www.tianqihoubao.com/aqi/zhengzhou.html (accessed 6 May 2020).

22. Weather Underground. http://www.wunderground.com (accessed 7 May 2020).

23. Chai G, He H, Sha Y, Zhai G, Zong S. Effect of PM2.5 on daily outpatient visits for respiratory diseases in Lanzhou, China. Sci Total Environ. 2019;649:1563-72.

24. Zhang F. Impacts of air pollutants and meteorological factors on outpatient visits for respiratory diseases [a master's degree thesis]: Lanzhou University; 2018.

25. Gasparrini A. Distributed Lag Linear and Non-Linear Models in R:The Package dlnm. J Stat Softw. 2011;43(8):1-20.

26. Gasparrini A, Armstrong B, Kenward MG. Distributed lag non-linear models. Stat Med. 2010;29(21):2224-34.

27. Roberts $S$, Martin MA. A distributed lag approach to fitting non-linear dose-response models in particulate matter air pollution time series investigations. Environ Res. 2007;104(2):193-200.

28. Wei J. The characteristics of air pollution in Shenyang and the analysis of the hysteresis effect on respiratory diseases [a master's degree thesis]: China medical university 2018.

29. Li HWP, Bo X, Wu X, Yang J, Liu H, Wei M, Hao P. Pollution characterization of major air pollutants and their impacts on resident health in Linyi City. Acta Sci Circum. 2020;40(8):2919-34.

30. Strosnider HM, Chang HH, Darrow LA, Liu Y, Vaidyanathan A, Strickland MJ. Age-Specific Associations of Ozone and Fine Particulate Matter with Respiratory Emergency Department Visits in the United States. Am J Respir Crit Care Med. 2019;199(7):88290.

31. Hong YZY, Ma Y, Wang S, Zhang J, Hou S, Chen K, Li H. Effects of air pollutants and meteorological factors on outpatient visitors for respiratory diseases in Shenyang. China Environmental Science. 2020;40(09):4077-90.

32. Sun YLL, Guo L, Zhu M, Lv Y. Comparative Analysis on Cities' Ambient Air Quality in South and North China. Environmental Protection Science. 2008;34(4):1-4.

33. LI JCS, Wang S, Xie T, Zhang Z, Fan W. Characteristics of temporal and spatial distribution of air pollutants over China during 2013-2014 and interdecadal variation of SO2 mass concentrations. China Sciencepaper. 2017;12(3):336-45.

34. Zhang JF, Jiang N, Duan SG, Sun YC, Hao Q, Zhang RQ. [Seasonal Chemical Composition Characteristics and Source Apportionment of PM2.5 in Zhengzhou]. Huan Jing Ke Xue. 2020;41(11):4813-24.

35. Liu Y, Ding H, Chang ST, et al. Exposure to air pollution and scarlet fever resurgence in China: a six-year surveillance study. Nat Commun. 2020;11(1):4229.

36. Platt SM, El Haddad I, Pieber SM, et al. Gasoline cars produce more carbonaceous particulate matter than modern filter-equipped diesel cars. Sci Rep. 2017;7(1):4926.

37. Almetwally AA, Bin-Jumah M, Allam AA. Ambient air pollution and its influence on human health and welfare: an overview. Environ Sci Pollut Res Int. 2020;27(20):24815-30.

38. Hsu CY, Chiang HC, Lin SL, Chen MJ, Lin TY, Chen YC. Elemental characterization and source apportionment of PM10 and PM2.5 in the western coastal area of central Taiwan. Sci Total Environ. 2016;541:1139-50.

39. Guan WJ, Zheng XY, Chung KF, Zhong NS. Impact of air pollution on the burden of chronic respiratory diseases in China: time for urgent action. Lancet. 2016;388(10054):1939-51.

40. Nodari S, Corulli A, Manerba A, Metra M, Apostoli P, Dei Cas L. Endothelial damage due to air pollution. Heart Int. 2006;2(2):115. 
41. Raulf-Heimsoth M, Hoffmeyer F, van Thriel C, Blaszkewicz M, Bunger J, Bruning T. Assessment of low dose effects of acute sulphur dioxide exposure on the airways using non-invasive methods. Arch Toxicol. 2010;84(2):121-7.

42. Lamichhane DK, Leem JH, Kim HC. Associations between Ambient Particulate Matter and Nitrogen Dioxide and Chronic Obstructive Pulmonary Diseases in Adults and Effect Modification by Demographic and Lifestyle Factors. Int J Environ Res Public Health. 2018;15(2):363.

43. Jin Y, Feng F,Duan LZQ, Wu W. Effects of ambient ozone on human respiratory system. Chin J Public Health. 2015;31(5):685-9.

44. Zhao Z, Chen R, Lin Z, et al. Ambient carbon monoxide associated with alleviated respiratory inflammation in healthy young adults. Environ Pollut. 2016;208(Pt A):294-8.

45. Ruiz J, Ameredes BT. The cellular effects of carbon monoxide in the airway. Curr Mol Med. 2013;13(1):94-108.

46. Zhao HLX, Li D, Tian H, Wang Q. Association between air pollution and respiratory diseases hospital outpatient visits in Lanzhou, China: A time-series analysis. Journal of Arid Land Resources Environment. 2020;34(8):133-9.

47. Vahedian M, Khanjani N, Mirzaee M, Koolivand A. Associations of short-term exposure to air pollution with respiratory hospital admissions in Arak, Iran. J Environ Health Sci Eng. 2017;15:17.

48. Vahedian M, Khanjani N, Mirzaee M, Koolivand A. Ambient air pollution and daily hospital admissions for cardiovascular diseases in Arak, Iran. ARYA Atheroscler. 2017;13(3):117-34.

49. Sood A, Shore SA. Adiponectin, Leptin, and Resistin in Asthma: Basic Mechanisms through Population Studies. Journal of allergy 2013; 2013: 785835.

50. Hermes GL, Rosenthal L, Montag A, McClintock MK. Social isolation and the inflammatory response: sex differences in the enduring effects of a prior stressor. Am J Physiol Regul Integr Comp Physiol. 2006;290(2):R273-82.

51. Tigala S, Sharma AR, Sachdeva K. Health risk assessment due to biomass smoke exposure in Indian indoor environment: An empirical approach using lung deposition model. Sci Total Environ. 2018;640-641:935-42.

52. Ding HLJ. Chronic disease prevalence and influencing factors among different occupational groups. Chinese Journal of Medical Management Sciences. 2019;9(6):59-63.

53. Du LHS, Jing W, Zhang X. Effects of active and passive smoking on lung function in female. Laboratory Medicine Clinic. 2019;16(08):1034-6.

54. Zhang YSY, Wang S, Shang K, Wang J, Li X, Kang Y. Relationship between air pollutant and respiratory diseases hospital outpatient visits in Beijing. China Environmental Science. 2014;34(9):2401-7.

55. Rissler J, Gudmundsson A, Nicklasson H, Swietlicki E, Wollmer P, Londahl J. Deposition efficiency of inhaled particles (15-5000 nm) related to breathing pattern and lung function: an experimental study in healthy children and adults. Part Fibre Toxicol. 2017;14(1):10.

56. Ferreira MS, Marson FAL, Wolf VLW, Ribeiro JD, Mendes RT. Lung function in obese children and adolescents without respiratory disease: a systematic review. BMC Pulm Med. 2020;20(1):281.

57. Metti AL, Best JR, Shaaban CE, Ganguli M, Rosano C. Longitudinal changes in physical function and physical activity in older adults. Age Ageing. 2018;47(4):558-64.

58. Bentayeb M, Simoni M, Baiz N, Norback D, Baldacci S, Maio S, Viegi G. \& Annesi Maesano, I. Adverse respiratory effects of outdoor air pollution in the elderly. Int J Tuberc Lung Dis. 2012;16(9):1149-61.

59. Orellano P, Quaranta N, Reynoso J, Balbi B, Vasquez J. Effect of outdoor air pollution on asthma exacerbations in children and adults: Systematic review and multilevel meta-analysis. PLoS One. 2017;12(3):e0174050.

\section{Figures}




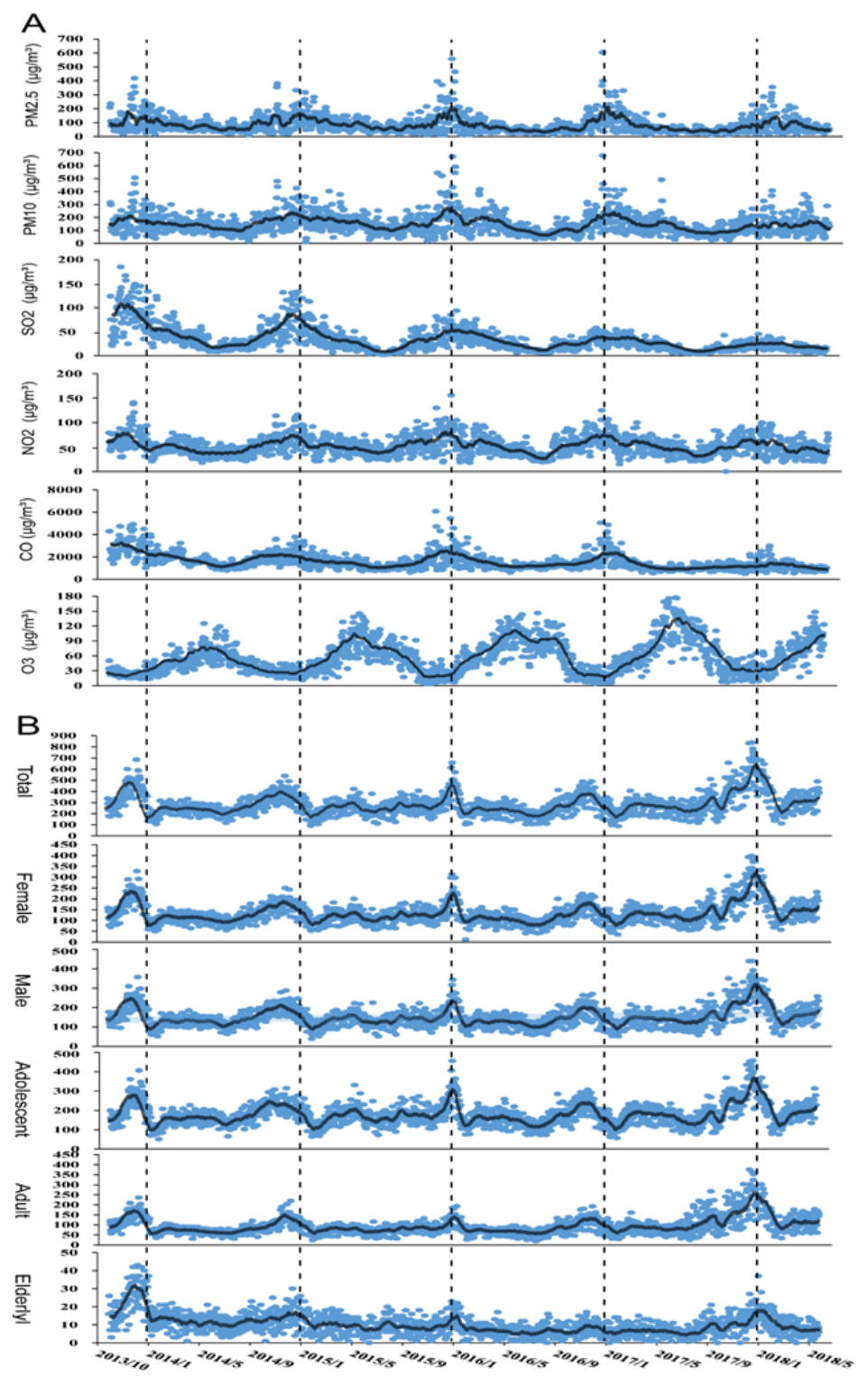

Figure 1

Daily mean concentrations of air pollutants (A) and daily URTI outpatient visits (B) in Zhengzhou, China, during the study period. URTI, upper respiratory tract infection. 


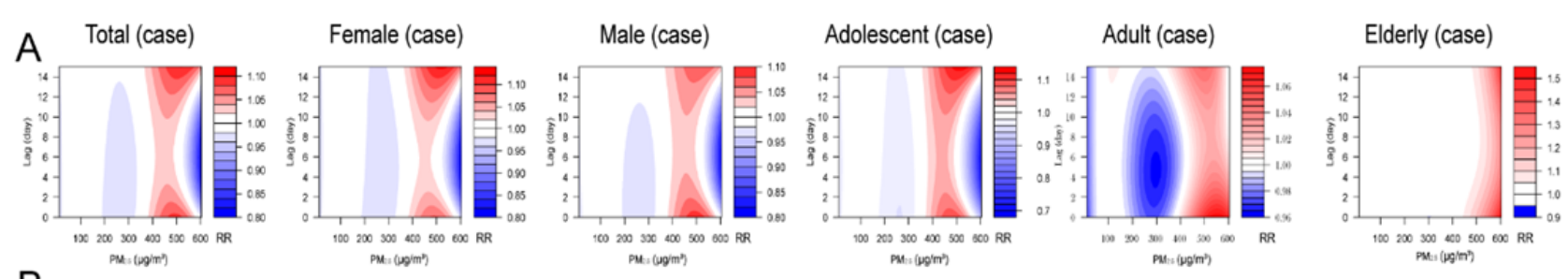

$\mathrm{B}$
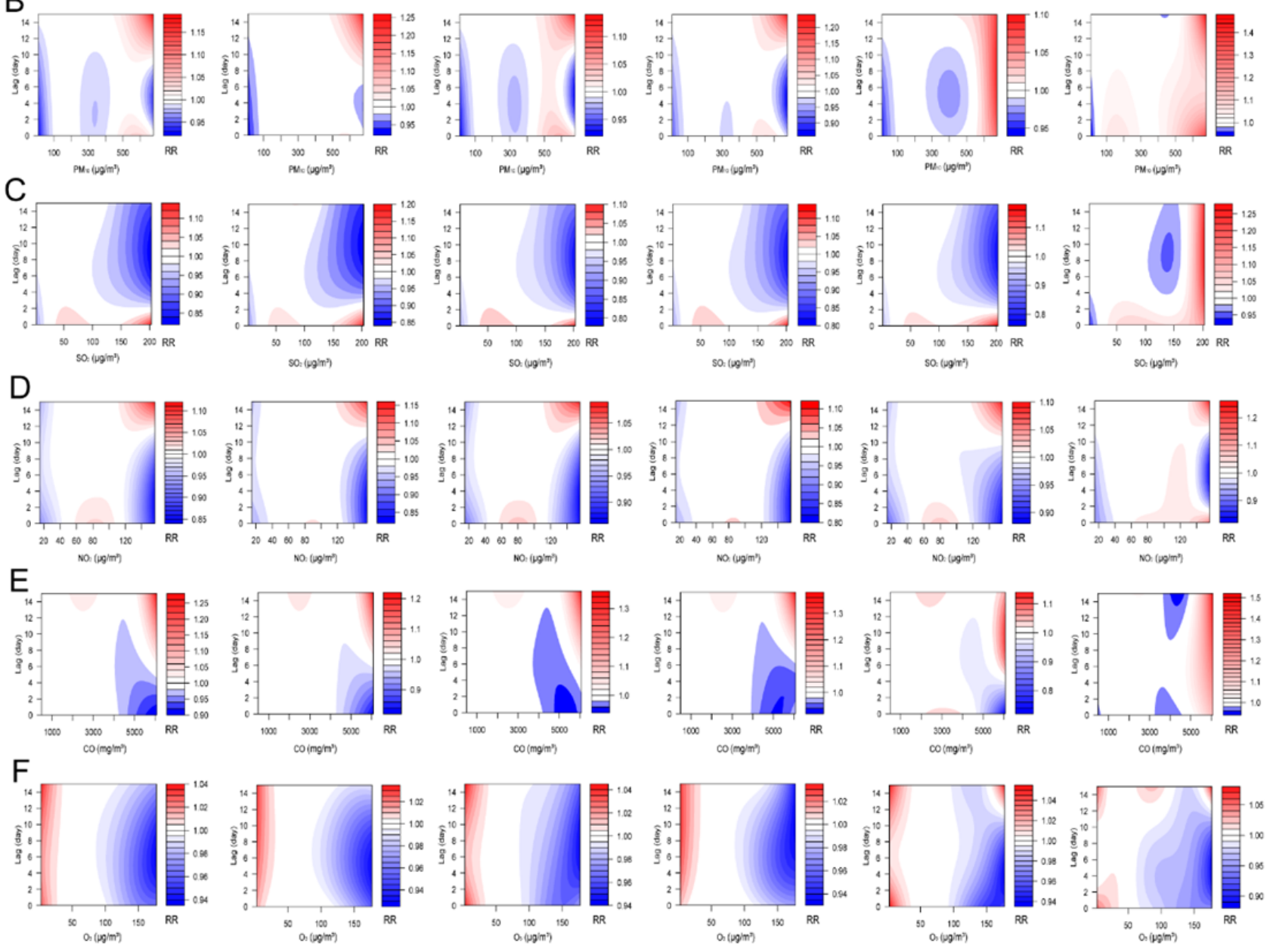

Figure 2

Contour plots of the exposure-response relationship for URTI outpatient visits and air pollutants in different genders and age subgroups. A, PM2.5; B, PM10; C, SO2; D, NO2; E, CO; F, 03. The gradient of color indicates the relative risk (RR). 

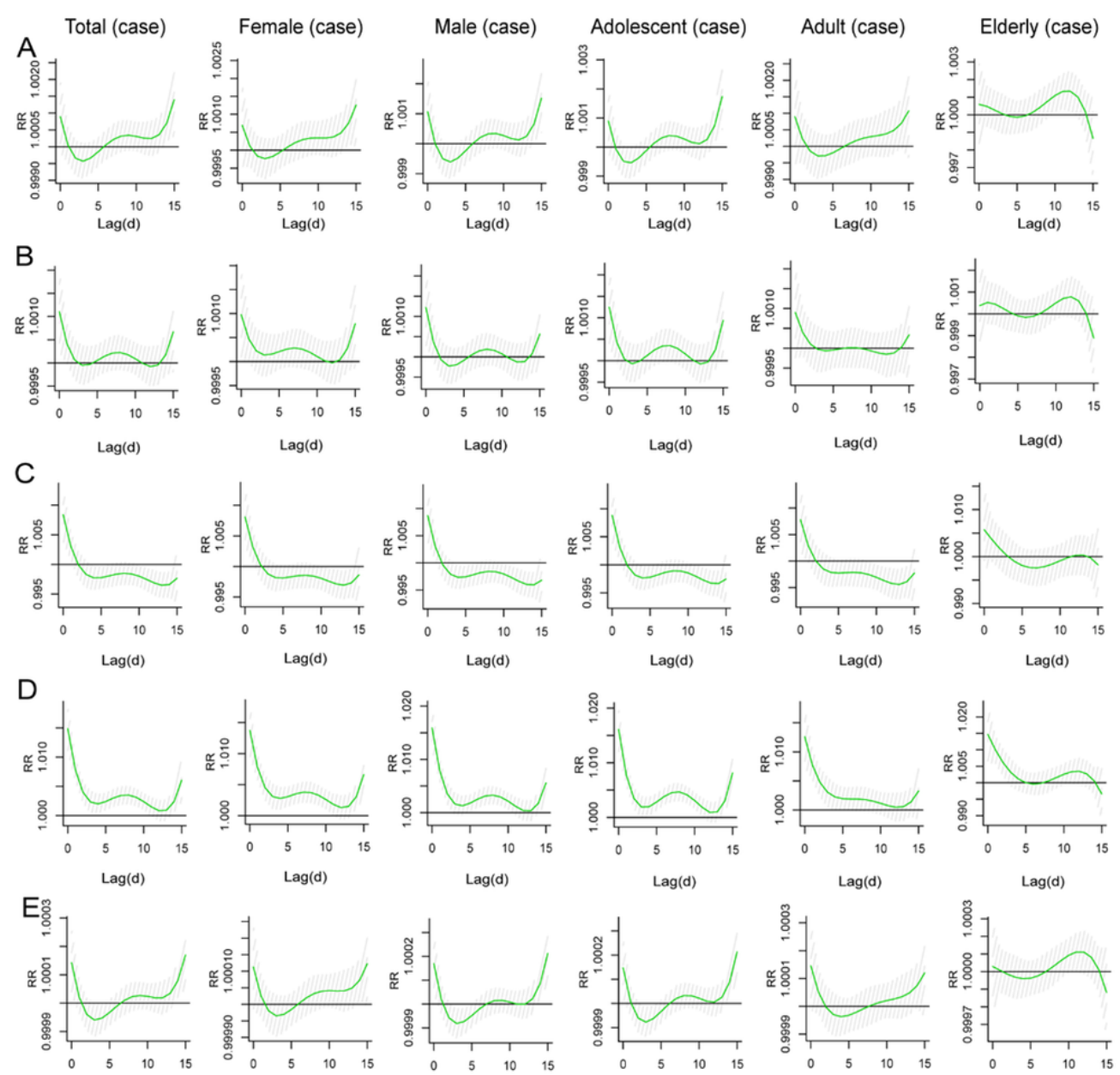

$\operatorname{Lag}(\mathrm{d})$

Lag(d)
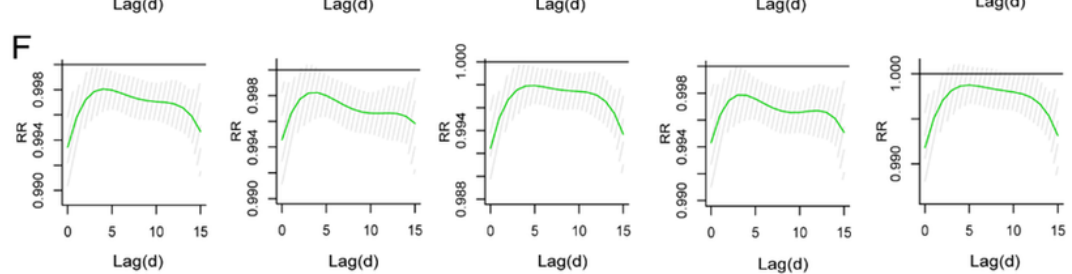

$\operatorname{Lag}(d)$

Figure 3

The relative risk of pollutants with $10 \mu \mathrm{g} / \mathrm{m} 3$ increasement on upper respiratory tract infection in different genders and age subgroups. A, PM2.5; B, PM10; C, SO2; D, NO2; E, CO; F, 03. RR, relative risk. The grey shadow area indicates the 95\% confidence interval.

\section{Supplementary Files}

This is a list of supplementary files associated with this preprint. Click to download.

- TableS1.docx 